\title{
Positive Psychology for Mental Wellbeing of UK Therapeutic Students: Relationships with Engagement, Motivation, Resilience and Self-Compassion
}

\author{
Yasuhiro Kotera $^{1}$ (D) Pauline Green ${ }^{1} \cdot$ David Sheffield $^{1}$
}

Accepted: 15 December 2020/Published online: 12 January 2021

(C) The Author(s) 2021

\begin{abstract}
This study aimed to examine the relationships between mental wellbeing and positive psychological constructs in therapeutic students (psychotherapy and occupational therapy students). The number of therapeutic students has increased recently; however, they suffer from poor mental health, which may be improved by potentiating their positive psychological constructs, bypassing mental health shame. Therapeutic students $(n=145)$ completed measures regarding positive psychological constructs, namely mental wellbeing, engagement, motivation, resilience, and self-compassion. Resilience and self-compassion predicted mental wellbeing, explaining a large effect. Self-compassion partially mediated the relationship between resilience and mental wellbeing. This study highlights the importance of positive psychological constructs, especially resilience and self-compassion, for mental wellbeing of therapeutic students.
\end{abstract}

Keywords Mental wellbeing $\cdot$ Positive psychology $\cdot$ Resilience $\cdot$ Self-compassion $\cdot$ Intrinsic motivation

In the UK, caring profession subjects - related to humans taking care of other humans, whether physically, mentally or spiritually (Kotera et al. 2018d) - are the most popular of all university disciplines. Of 700,000 students who applied to undergraduate programmes in UK universities, $60 \%$ of them applied to this discipline in 2014 (McGhee 2015). More than one in every five students studied either an undergraduate or postgraduate caring profession subject programme in the academic year 2015-2016 (Higher Education Statistics Agency 2017). This is unique to the UK. For example, business is the most popular subject in the USA (National Center for Education Statistics 2016) and in Germany (Muller 2016) and social science is most popular in Japan (Ministry of Education, Culture, Sports, Science and Technology-Japan 2015). One notable reason for this popularity in caring subjects in the UK relates to stable

Yasuhiro Kotera

y.kotera@derby.ac.uk; yasuhirokotera@gmail.com

1 Human Sciences Research Centre, University of Derby, Kedleston Road, Derby DE22 1GB, UK 
post-study employment: for instance, almost all the occupational therapy students are employed within 6 months of graduation (Association of Graduate Careers Advisory Services 2017).

Caring profession subjects include allied health (e.g. occupational therapy, physiotherapy), psychotherapy, nursing, social work and teaching (Kotera et al. 2018d). Despite its popularity, the mental wellbeing of caring subject students is challenging: UK social work students have high levels of depression, anxiety and stress (Kotera et al. 2019b); nursing students have poor mental wellbeing (Kotera et al. 2019); and more than one-third of occupational therapy and psychotherapy students have depression and low self-esteem (Boellinghaus et al. 2013). As these students are dealing, or will deal with patients' lives, high rates of poor mental wellbeing, which can cause poor decisions (Blackmore et al. 2007; Brooks et al. 2002) is alarming. Mentally distressed healthcare workers are more likely to make errors, negatively impacting on client safety, which is the central element in education for caring profession (Melnyk et al. 2018; The Quality Assurance Agency for Higher Education 2013). Moreover, this relates to the current emphasis, associated with coronavirus disease 2019 (COVID-19), that caring professionals need to take care of themselves in order to offer care for others (Kotera et al. 2020a, b; Spoorthy et al. 2020).

Among the caring disciplines, this study focused on therapeutic students (psychotherapy students and occupational therapy students; Kotera et al. 2019c), because the number of students in these programmes have expanded recently due to the government's prioritised focus on mental health (Complete University Guide 2018).

\section{Usefulness of Positive Psychology for Mental Wellbeing}

One contributing factor to caring students' poor mental wellbeing may be their hesitancy to ask for help. For example, high caregiver identity was related to high shame about mental health problems (mental health shame; Kotera et al. 2019d) among students in caring subjects (Kotera et al. 2019b). Further, mental health shame was a positive predictor of mental health problems in therapeutic students (Kotera et al. 2019c). This may imply that offering these students 'mental health' support directly would not be effective, as they would not fully engage in such support because of shame (Kotera et al. 2018b). On the other hand, positive psychological approaches may be effective as these approaches could bypass their high mental health shame, focusing on nurturing what assets they have (Joseph and Linley 2006; Kotera and Ting 2019). Indeed, the importance of positive psychology has been recognised among therapeutic practitioners (Bannigan 2002; Joseph and Linley 2006; Maki and Endo 2018).

Positive psychology focuses on happiness and positivity, aiming to further strengthen one's strengths and values (Seligman and Csikszentmihalyi 2000), as opposed to traditional psychology which primarily focuses on pathologies (i.e. what is impaired), aiming to dissect them out. Positive psychology perceives that all people have the potential (given the right skills and contexts), instead of focusing on what people lack (Kashdan and Ciarrochi 2013). Positive psychological approaches are recommended to prevent mental health problems in the general population (Forsman et al. 2015; Kobau et al. 2011) and in UK students (Denovan and Macaskill 2017).

Intervention studies have reported promising results. Acceptance and commitment therapy increased positive psychological outcomes and decreased depression in a randomised controlled trial (Bohlmeijer et al. 2015). A 5-week online positive psychology intervention, 
focusing on positive emotions (e.g. engagement and meaning), increased pregnant women's life satisfaction and reduced depression (Corno et al. 2018). PhD students' mental distress was alleviated after 8-week engagement and motivation training (Marais et al. 2018). Moreover, a 10 -year longitudinal study on adults' positive psychology and mental distress noted a relationship between heightened positive psychology constructs and mitigated mental distress (Keyes et al. 2010). Likewise, positive psychological constructs predicted large variance (28$53 \%$ ) of mood disorders in a 3-year longitudinal study (Schotanus-Dijkstra et al. 2016). It is unsurprising that positive psychology has been recommended to counsellors who help empower clients to accomplish mental health, wellbeing and career goals (American Psychological Association 2015) by increasing their happiness and developing their strengths (Haktanir et al. 2016). These findings support the significant relationships between positive psychology constructs and mental wellbeing.

Academic engagement (hereafter 'engagement') is a particularly important positive psychological construct in higher education for its associations with various student outcomes including mental health (Liébana-Presa et al. 2014; Rogers et al. 2017), attainment (CasusoHolgado et al. 2013; Neel and Fuligni 2013) and intrinsic motivation (Armbruster et al. 2009; Bicket et al. 2010). Engagement refers to the degree students are committed to make an effort in their academic work (Newman et al. 1992), and is related to mental health in 410 Australian students (Turner et al. 2017). Students' commitment to their academic work is positively related to their mental wellbeing. The positive associations between engagement and mental wellbeing have been found in student populations in other countries too (e.g., Datu 2018; Suárez-Colorado et al. 2019). However, research into these relationships in UK university students has been scarce, particularly in UK therapeutic students.

Intrinsic motivation, closely related with engagement, is another key positive psychological construct, related to mental wellbeing (Baard et al. 2004; Bailey and Phillips 2016; Locke and Latham 2004). Intrinsic motivation, opposing extrinsic motivation, is one type of motivation in Self-Determination Theory, one of the most researched motivation theories (Deci and Ryan 1985). Self-Determination Theory presumes that every individual has an innate predisposition to direct their psychological power to self-actualisation, while maintaining social connections (Deci and Ryan 1985). Intrinsic motivation is present in activities that are naturally satisfying and fulfilling (i.e., being involved in the activity itself is a reward), whereas extrinsic motivation is relevant to activities that are a means to an end (e.g., money and status that can be brought as a result of the activities; Kotera et al. 2018d).

Intrinsic motivation is related to positive outcomes including better performance (Baard et al. 2004), wellbeing (Bailey and Phillips 2016), life satisfaction (Locke and Latham 2004), prosocial behaviour (Gagné 2003) and ethical judgement (Kotera et al. 2018a). In contrast, extrinsic motivation is related to negative outcomes such as burnout (Houkes et al. 2003), shame (Kotera et al. 2018a), depression (Blais et al. 1993), compromised performance (Vallerand 1997) and poor ethical judgement (Kotera et al. 2018a). Students' intrinsic motivation was related to academic performance in Israeli nursing students (Khalaila 2015) and meaningfulness in Norwegian health and social work students (Utvær 2014); however, these relationships have not been thoroughly investigated in UK therapeutic students in relation to mental health.

Though emotional resilience (hereafter 'resilience') has been defined in varied ways (e.g. Pooley and Cohen 2010; Ungar 2008), resilience is considered a generic term entailing internal resources to help an individual to overcome adversity, and expand themselves from such experiences (Grant and Kinman 2014). The importance of resilience in practice has been noted 
in the professional ethical and capability framework (e.g. British Association for Counselling and Psychotherapy 2018; College of Occupational Therapists 2014). Resilient practitioners are aware of their strengths and agency, and are able to reframe adversity as an opportunity for growth (Russ et al. 2009; Harrison 2013). Indeed, resilient people are not exempt from being affected by life challenges; however, they tend not to be overwhelmed by those challenges permanently (Tugade and Fredrickson 2004). Enhancing resilience was associated with better mental wellbeing, along with improved psychological outcomes such as self-efficacy, mindfulness and compassion (Robertson et al. 2015). Resilience can be maintained with psychological resources such as motivation, reframing life challenges into growing experiences (Bryan et al. 2017) — essential to therapeutic students (British Association for Counselling and Psychotherapy 2018; College of Occupational Therapists 2014).

Lastly, self-compassion has been increasingly paid attention to, for its relevance to mental wellbeing (Ehret et al. 2015; Kotera et al. 2018b, 2019; Muris et al. 2018). Self-compassionbeing understanding and accepting of one's weaknesses and inadequacies (Gilbert 2009) protects mental wellbeing by supporting resilience (Trompetter et al. 2017). Self-compassion is strongly related to mental wellbeing (Ehret et al. 2015; Hayter and Dorstyn 2014; Muris et al. 2018), and a significant predictor of mental wellbeing in UK social work students (Kotera et al. 2019b). In addition, numerous studies reported that self-compassion mediated the relationship between positive mental constructs and mental wellbeing (Beaumont et al. 2016; Fong and Loi 2016; Neff and Mcgehee 2010; Zhang et al. 2016), suggesting that self-compassion would be a mediator of the relationship between resilience and mental wellbeing (Trompetter et al. 2017). Resilience Theory posits that how we cope with difficulties, rather than the difficulties themselves, matters more to our wellbeing (Van Breda 2018). Treating oneself in a caring manner is conducive to one's coping, emphasising one's strengths in the process of resilience (Fergus and Zimmerman 2005). Moreover, Social Mentality Theory suggests how we treat ourselves originates from how we treat others (Gilbert 2000). Therapeutic students aspire to help others; therefore, based on this theory, they may be also willing to help themselves. Accordingly, whether self-compassion would mediate the relationship between resilience and mental wellbeing in therapeutic students needs to be examined.

Despite the significant relationships between mental wellbeing and these positive psychological constructs, these have not yet been explored among UK therapeutic students in depth. This study, therefore, aimed to explore the relationships between mental wellbeing, engagement, motivation, resilience and self-compassion. Two sets of hypotheses were tested:

H1: Mental wellbeing will be associated with (a) engagement, (b) motivation, (c) resilience and (d) self-compassion.

$\mathrm{H} 2$ : Self-compassion will mediate the relationship between resilience and mental wellbeing.

\section{Methods}

\section{Participants}

Participants were aged 18 years or older and enrolled on an occupational therapy or psychotherapy programme at a UK university in the Midlands region. One hundred and forty-five students of 166 full-time students completed the self-report measures about wellbeing, engagement, motivation, resilience and self-compassion. This is a parallel study with another study exploring their mental health attitudes. The findings are reported elsewhere. 


\section{Materials}

Mental wellbeing was evaluated using the seven-item Short Warwick-Edinburgh Mental Wellbeing Scale (SWEMWBS; Stewart-Brown et al. 2009), shortened version of the original 14-item scale (Stewart-Brown and Janmohamed 2008). Though how to measure mental wellbeing is still open to debate, this scale is one of the most established wellbeing scales, and its holistic appraisal on mental wellbeing fits with the purpose of this present study (Cooke et al. 2016). Reflecting on the past 2 weeks, students respond to the seven items, regarding both hedonic and eudaimonic wellbeing (e.g., 'I've been dealing with problems well'), on a five-point Likert scale ( $1=$ 'None of the time' to $5=$ 'All of the time'). SWEMWBS had high internal consistency ( $\alpha=.85$; Stewart-Brown et al. 2009).

Engagement was examined using the Utrecht Work Engagement Scale for Students (UWES$S)$, a 17 -item on a seven-point Likert scale $(0=$ 'Never' to $6=$ 'Always (everyday)' $)$ considering how active and confident students feel towards their academic activities (Schaufeli and Bakker 2004). The three subscales of UWES-S relates to vigour, that is mental energy leading to a substantial effort in academic work (six items including 'I am very resilient, mentally, as far as my studies are concerned'), dedication, namely commitment to academic work (five items including 'My study inspires me'), and absorption, regarded as positive immersion in academic work (six items including 'When I am studying, I forget everything else around me.') (Schaufeli et al. 2002). UWES-S had high internal consistency ( $\alpha=.63-.81$; Schaufeli and Bakker 2004). In this study, the average of the total engagement score was used (Schaufeli and Bakker 2004).

The Academic Motivation Scale (AMS; Vallerand et al. 1992), comprising 28 items assessing three types of motivation categorised into seven subtypes: (i) amotivation, (ii) extrinsic motivation (external, introjected, and identified regulation) and (iii) intrinsic motivation (to know, to accomplish and to experience stimulation). Students respond to items asking why they go to university (e.g. 'I don't know; I can't understand what I am doing in school' for amotivation, 'Because I want to have "the good life" later on.' for extrinsic motivation, and 'Because I experience pleasure and satisfaction while learning new things' for intrinsic motivation; the wording was adjusted to the UK higher education, e.g. 'school' was changed to 'university'), on a seven-point Likert scale ( $1=$ 'Does not correspond at all' to $7=$ 'Corresponds exactly'). AMS had adequate to high internal consistency ( $\alpha$ $=.62-.91$; Vallerand et al. 1992).

Resilience was measured using the Brief Resilience Scale (BRS), a six-item scale measuring the ability to bounce back from difficulties (Smith et al. 2008). Students respond to the six items (e.g. 'I usually come through difficult times with little trouble') on five-point Likert scale ( $1=$ 'Strongly Disagree' to $5=$ 'Strongly Agree') for the items 1, 3 and 5, and the rest of the inverted Likert scale (i.e. $5=$ 'Strongly Disagree' to $1=$ 'Strongly Agree'). BRS had high internal consistency ( $\alpha=.80-.91$; Smith et al. 2008).

Lastly, self-compassion was assessed using the Self-Compassion Scale-Short Form (SCS-SF; Raes et al. 2011), a 12-item on five-point Likert scale to evaluate how consistently you behave kindly towards yourself in difficult situations $(0=$ 'Almost never' to $5=$ 'Almost always'). Items include 'I try to be understanding and patient towards those aspects of my personality I don't like', and items 1, 4, 8, 9, 11 and 12 are responded inversely ( $0=$ 'Almost always' to $5=$ 'Almost never'). SCS-SF had high internal consistency ( $\alpha=.86$; Raes et al. 2011).

\section{Procedure}

Once the consent form had been completed, students were presented with the scales, followed by the debrief. In case students were distressed by attending the study, 
information about available mental health support, inside and outside the university, was provided, to treat any issues in a careful manner. All materials were provided in hard copy. Ethics approval was obtained from the university research ethics committee.

After screening for the outliers and assumptions of parametric tests, correlations and multiple regression analyses were performed to explore relationships among those constructs. Followingly, path analyses were conducted to identify whether self-compassion mediates the relationship between resilience and mental wellbeing. SPSS version 25 and Process Macro version 3 (Hayes 2018) were used for these analyses.

\section{Results}

Demographic data of our sample were $M_{\mathrm{age}}=26.80, \mathrm{SD}_{\mathrm{age}}=8.64, \mathrm{RNG}_{\mathrm{age}}=17-52$ years old; 15 males and 130 females; 133 undergraduates and 12 postgraduates; 76 occupational therapy students and 69 psychotherapy students; 131 British, 7 other European, 4 Asian, 2 African and 1 North American. Gender balance of our sample (10\% male) was similar to occupational therapists and counsellors (Brown 2017; Grant et al. 2004), maintaining good representativeness.

\section{Correlations Between Mental Wellbeing, Engagement, Motivation, Resilience and Self-Compassion (H1)}

Eight scores in amotivation were identified as outliers, using the outlier labelling rule (Hoaglin and Iglewicz 2012), so were winsorised (Tukey 1962). All variables had high internal consistency $(\alpha=.82-.91$; Table 1$)$. Since engagement, motivation and selfcompassion were not normally distributed (Shapiro-Wilk, $p<.05$ ), all the sub/scales were square-root-transformed. Pearson's correlation was calculated to explore the relationships between mental wellbeing, engagement, motivation, resilience and selfcompassion (Table 1).

Mental wellbeing was positively related with engagement, intrinsic motivation, resilience and self-compassion, and negatively related with gender and amotivation. Only extrinsic motivation was not related with mental wellbeing. Engagement was positively related with

Table 1 Descriptive statistics and correlations between mental wellbeing, academic engagement, motivation, resilience and self-compassion in $145 \mathrm{UK}$ therapeutic students

\begin{tabular}{|c|c|c|c|c|c|c|c|c|c|c|c|c|c|}
\hline & & $M$ & $\mathrm{SD}$ & $\alpha$ & 1 & 2 & 3 & 4 & 5 & 6 & 7 & 8 & 9 \\
\hline 1 & $\mathrm{GN}(\mathrm{M}=1, \mathrm{~F}=2)$ & 15 males, & 130 fen & ales & - & & & & & & & & \\
\hline 2 & Age & 26.80 & 8.64 & & .06 & - & & & & & & & \\
\hline 3 & Mental wellbeing & 23.94 & 4.85 & .85 & $-.18^{*}$ & $.18^{*}$ & - & & & & & & \\
\hline 4 & Engagement & 3.81 & .97 & .91 & .05 & $.20 *$ & $.32 * *$ & - & & & & & \\
\hline 5 & $\begin{array}{l}\text { Intrinsic } \\
\text { motivation }\end{array}$ & 18.50 & 4.64 & .82 & -.02 & $.22 * *$ & $.24 * *$ & $.52 * *$ & - & & & & \\
\hline 6 & $\begin{array}{l}\text { Extrinsic } \\
\text { motivation }\end{array}$ & 20.81 & 4.23 & .87 & .02 & -.03 & .05 & $.28 * *$ & $.40 * *$ & - & & & \\
\hline 7 & Amotivation & 6.08 & 2.97 & .83 & -.04 & -.01 & $-.21 *$ & $-.33 * *$ & -.11 & -.06 & - & & \\
\hline 8 & Resilience & 19.86 & 5.58 & .83 & -.14 & $.20 *$ & $.50 * *$ & $.27 * *$ & .09 & -.08 & -.13 & - & \\
\hline 9 & Self-compassion & 34.05 & 9.52 & .84 & -.16 & .15 & $.61 * *$ & $.21 * *$ & .10 & $-.22 * *$ & $-.26 * *$ & $.60 * *$ & 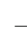 \\
\hline
\end{tabular}

$* p<.05 ; * * p<.01$ 
intrinsic motivation, extrinsic motivation, resilience and self-compassion, while negatively related with amotivation.

\section{Positive Psychological Predictors of Mental Wellbeing (H1)}

To identify predictive relationships with mental wellbeing, multiple regression analyses were performed. Engagement, intrinsic motivation, amotivation, resilience and self-compassion (significant correlates of mental wellbeing) were entered as predictor variables, and mental wellbeing was entered as an outcome variable. Multicollinearity was not a concern (VIFs < 10). These positive psychological predictor variables accounted for $35 \%$ for mental wellbeing, a large effect size. Resilience and self-compassion were significant positive predictors for mental wellbeing. Self-compassion was the strongest predictor of mental health among all the positive psychological constructs. H1 was partially supported (H1c and H1d) (Table 2).

\section{Self-Compassion as a Mediator Between Resilience and Mental Wellbeing (H2)}

Finally, to examine whether self-compassion mediated the relationship between resilience and wellbeing, path analyses were conducted using model 4 in the Process macro (parallel mediation model; Hayes 2018).

As summarised in Fig. 1, there was a significant indirect effect of resilience on mental wellbeing through self-compassion, $b=.22$, BCa CI $[.13, .33]$, which explained $15 \%$ of the variance in mental wellbeing, and accounted for $56 \%$ of the total effect, a large effect size. The direct effect of resilience on mental wellbeing, controlling for self-compassion, was also significant, $b=.17, t(141)=2.70, p=.008$, implying that resilience could directly predict the variance in mental wellbeing. The total effect of resilience on mental wellbeing, including self-compassion, was also significant, $b=.39, t(142)=6.93, p<.001$. In total, $25 \%$ of the variance in mental wellbeing was explained by resilience, controlling for self-compassion.

Table 2 Multiple regression: engagement, motivation, resilience and self-compassion for mental wellbeing in 145 UK therapeutic students

\begin{tabular}{lccc}
\hline & \multicolumn{2}{l}{ Mental wellbeing } & \\
\cline { 2 - 4 } & $B$ & $\mathrm{SE}_{\mathrm{B}}$ & $\beta$ \\
\hline Step 1 & & & $-.19^{*}$ \\
GN $(1=\mathrm{M}, 2=\mathrm{F})$ & -.21 & .09 & $.19^{*}$ \\
Age & .01 & .01 & \\
Adj. $R^{2}$ & .06 & & -.09 \\
Step 2 & & & .04 \\
GN $(1=\mathrm{M}, 2=\mathrm{F})$ & -.10 & .07 & .10 \\
Age & .002 & .16 & .11 \\
Engagement & .20 & .07 & .03 \\
Intrinsic motivation & .10 & .07 & $.18^{*}$ \\
Amotivation & -.03 & .06 & $.44^{* *}$ \\
Resilience & .14 & .06 & \\
Self-compassion & .32 & & \\
$\Delta$ Adj. $R^{2}$ & .35 & & \\
\hline
\end{tabular}

$* p<.05 ; * * p<.01$ 
Because all the paths were significant, self-compassion partially mediated the relationship between resilience and mental wellbeing; $\mathrm{H} 2$ was supported.

\section{Discussion}

This study investigated the relationships between mental wellbeing and positive psychological constructs, namely engagement, motivation, resilience and self-compassion in UK therapeutic students (i.e. psychotherapy students and occupational therapy students). Their mental wellbeing was positively associated with engagement, intrinsic motivation, resilience and self-compassion, while negatively associated with amotivation. Extrinsic motivation was not associated with mental wellbeing. Self-compassion and resilience were significant predictors of mental wellbeing, and self-compassion was the strongest predictor. Lastly, self-compassion partially mediated the relationship between resilience and mental wellbeing.

\section{Correlations Between Mental Wellbeing and Positive Psychological Constructs}

In line with previous research, all the positive psychological constructs (engagement, intrinsic motivation, resilience and self-compassion) were related to mental wellbeing. Resilience and self-compassion, in particular, had large effect relationships $(r>.50)$. Students who are (a) well-engaged with academic work, (b) passionate about academic work, (c) able to bounce back from challenges and (d) understanding towards themselves tend to have a high level of mental wellbeing. Previously, these relationships between mental wellbeing and positive psychology have been reported in other student populations (Kotera and Ting 2019; Kotera et al. 2018b), and our findings report that the relationships were identified in the UK therapeutic students too. These identified relationships can help substantiate practitioners' experience, noting that positive mental resources are essential in the therapeutic field (Vandenberghe and Silvestre 2014). Both occupational therapists and psychotherapists work in collaboration with other professionals, and a wide range of clients. Considering the

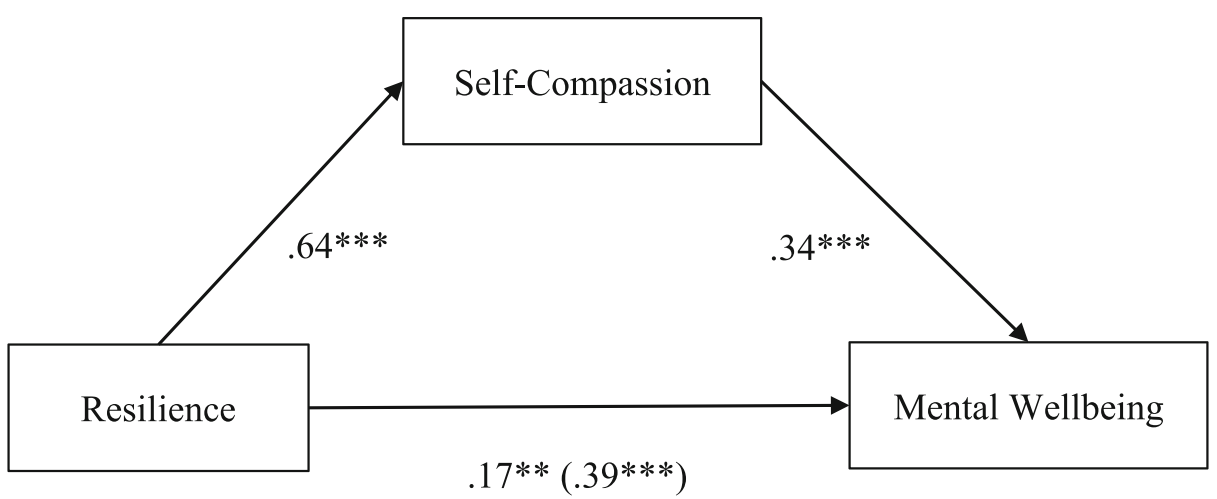

Fig. 1 Parallel mediation model: resilience as a predictor of mental wellbeing, mediated by self-compassion. The confidence interval for the indirect effect is a BCa bootstrapped CI based on 5000 samples. $* * p<.01 ; * * * p<$ .001 ; direct effect (total effect) 
contagious nature of positive emotions, recognising positive psychology is useful to trainees and practitioners (Bannigan 2002; Dunn 2017).

This may suggest that educators and university counsellors may need to consider embedding a session or event focusing on potentiating students' positive psychological resources in their curriculum and services. For example, an 8-week mindfulness training was effective to strengthen resilience to mental distress in a UK general student sample (Galante et al. 2018). Weekly mindfulness sessions over a month improved occupational therapy students' self-awareness and stress management skills (Stew 2011). These types of training may benefit from considering the holistic nature of positive psychology, reflecting several key areas of student lives (Hall et al. 2015), instead of solely focusing on their academic life. Unsurprisingly, positive psychological approaches were recommended for international therapists to learn as an intervention, for its applicability to diverse client issues (Lenz et al. 2018). Training in positive psychology would be especially beneficial to therapeutic students. Future research needs to explore the effects of such interventions targeting positive psychology, leading to better mental wellbeing.

\section{Self-Compassion and Resilience Predict Mental Wellbeing}

Self-compassion and resilience were identified as predictors of mental wellbeing, and selfcompassion was the strongest predictor of all the studied variables. Resilience has been emphasised in the psychotherapy and occupational therapy fields (British Association for Counselling and Psychotherapy 2018; College of Occupational Therapists 2014), and our findings echoed this. Students who study in these programmes are familiar with, and cognisant of the importance of resilience (Kotera et al. 2018a). Resilience research has been active in the recent years; however, little has focused on this student group. The ability to bounce back from the difficulties was deemed to be important to mental wellbeing of the UK therapeutic students. As mentioned above, mindfulness is one way to potentiate resilience (Galante et al. 2018; Stew 2011).

Likewise, self-compassion has been a focus in mental health research recently, and its importance has been reported (Kotera et al. 2018c). In the UK, building a compassionate culture among caring professionals has been endorsed (Department of Health, 2013); however, compassion towards practitioners themselves has been rather under-emphasised (Mckenna and Mellson 2013). Implementing self-compassion training to therapeutic students may be useful, aiming for better self-care and mental wellbeing (Christopher and Maris 2010). For instance, a session during the orientation week may be beneficial and effective, because informing students of mental wellbeing and coping skills in the beginning of their programme could prepare them for the potential academic stress, which can support students' help-seeking, resulting in better clinical outcomes. Additionally, due to the contagious nature of compassion (Fowler and Christakis 2010), tutors may also benefit from this type of event as compassion was associated with tutors' mental health (Jennings and Greenberg 2009). Future research should examine the effects of self-compassion training on therapeutic students' mental health.

\section{Self-Compassion Mediates Resilience-Mental Wellbeing}

Lastly, our path analyses revealed that self-compassion partially mediated the relationship between resilience and mental wellbeing. Self-compassion strengthens the significant impact of resilience on mental wellbeing. Again, this may highlight the importance of these two constructs for mental wellbeing of therapeutic students (Dunn 2017). While resilience is highly recognised in therapeutic students and their professional bodies (British Association for Counselling and Psychotherapy 2018; 
College of Occupational Therapists 2014), self-compassion is still a new concept (Mckenna and Mellson 2013), indicating a need for more recognition of self-compassion in this field. Future research needs to evaluate the effects of self-compassion education and training on mental wellbeing of therapeutic students.

\section{Limitations}

Several limitations to this study need to be noted. Firstly, the participants were recruited through opportunity sampling at one university, limiting the generalisability of the findings. Secondly, this study examined a combination of occupational therapy and psychotherapy students, as each sample size alone did not reach the required sample size calculated on power analysis ( $n=114$; Faul et al. 2009). Future research should explore these groups of students separately to further understand the specific characteristics of each student group. However, in the current sample, there were no differences in the measures between the groups $(p \geqq .24)$. Thirdly, measuring these constructs using self-report measures might compromise their accuracy (e.g. response bias [Kotera et al. 2020a], and validity [Kotera and Sheffield 2020]). Additional qualitative data (e.g. a focus group discussion with students) could offer more indepth findings. Fourthly, the causal directions of these related psychological constructs have not been evaluated. Longitudinal studies would help understand the temporal patterning of the identified relationships and may help design approaches that would increase our understanding of causality.

\section{Conclusion}

The poor mental wellbeing of this expanding student group may be improved by potentiating their positive psychological constructs, which could bypass their high mental health shame. This study examined the relationships between mental wellbeing and positive psychological constructs, namely academic engagement, motivation, resilience and self-compassion of UK therapeutic students. Their mental wellbeing was associated with engagement, intrinsic motivation, resilience and self-compassion. Self-compassion and resilience were significant predictors of mental wellbeing. Lastly, self-compassion partially mediated the relationship between resilience and mental wellbeing. Findings highlight the importance of positive psychology in a therapeutic student group, and will help educators, practitioners, researchers and students to identify alternative approaches to improve their mental wellbeing.

All procedures followed were in accordance with the ethical standards of the responsible committee on human experimentation (institutional and national) and with the Helsinki Declaration of 1975, as revised in 2000 (5). Informed consent was obtained from all patients for being included in the study.

\section{Compliance with Ethical Standards}

Conflict of Interest The authors declare that they have no conflict of interest.

Ethics Approval and Consent to participate All procedures followed were in accordance with the ethical standards of the responsible committee on human experimentation (University of Derby, UK) and with the Helsinki Declaration of 1975, as revised in 2000(5). Informed consent was obtained from all patients prior to being included in the study. 
Open Access This article is licensed under a Creative Commons Attribution 4.0 International License, which permits use, sharing, adaptation, distribution and reproduction in any medium or format, as long as you give appropriate credit to the original author(s) and the source, provide a link to the Creative Commons licence, and indicate if changes were made. The images or other third party material in this article are included in the article's Creative Commons licence, unless indicated otherwise in a credit line to the material. If material is not included in the article's Creative Commons licence and your intended use is not permitted by statutory regulation or exceeds the permitted use, you will need to obtain permission directly from the copyright holder. To view a copy of this licence, visit http://creativecommons.org/licenses/by/4.0/.

\section{References}

American Psychological Association (2015). The road to resilience. Retrieved from http://www.apa. org/helpcenter/road-resilience.aspx. Accessed 31 Jul 2020.

Armbruster, P., Patel, M., Johnson, E., \& Weiss, M. (2009). Active learning and student-centered pedagogy improve student attitudes and performance in introductory biology. CBE Life Sciences Education, 8(3), 203213. https://doi.org/10.1187/cbe.09-03-0025.

Association of Graduate Careers Advisory Services (2017) What can I do with my degree? Occupational therapy. Retrieved from https:/www.prospects.ac.uk/careers-advice/what-can-i-do-with-my-degree/occupationaltherapy. Accessed 31 Jul 2020.

Baard, P., Deci, E., \& Ryan, R. (2004). Intrinsic need satisfaction: A motivational basis of performance and wellbeing in two work settings. Journal of Applied Social Psychology, 34(10), 2045-2068. https://doi. org/10.1111/j.1559-1816.2004.tb02690.x.

Bailey, T., \& Phillips, L. (2016). The influence of motivation and adaptation on students' subjective well-being, meaning in life and academic performance. Higher Education Research and Development, 35(2), 201-216. https://doi.org/10.1080/07294360.2015.1087474.

Bannigan, K. (2002). A positive attitude is a professional imperative. British Journal of Occupational Therapy, 65(9), 397. https://doi.org/10.1177/030802260206500901.

Beaumont, E., Durkin, M., Hollins Martin, C., \& Carson, J. (2016). A proposal to support student therapists to develop compassion for self and others through Compassionate Mind Training. The Arts in Psychotherapy, 50, 111-118. https://doi.org/10.1016/j.aip.2016.06.005.

Bicket, M., Misra, S., Wright, S. M., \& Shochet, R. (2010). Medical student engagement and leadership within a new learning community. BMC Medical Education, 10, 20. https://doi.org/10.1186/1472-6920-10-20.

Blackmore, E. R., Stansfeld, S. A., Weller, I., Munce, S., Zagorski, B. M., \& Stewart, D. E. (2007). Major depressive episodes and work stress: Results from a national population survey. American Journal of Public Health, 97(11), 2088-2093. https://doi.org/10.2105/AJPH.2006.104406.

Blais, M. R., Lachance, L., Vallerand, R. J., Brie're, N. M., \& Riddle, A. S. (1993). The Blais inventory of work motivation [French]. Revue Que'-be'coise de Psychologie, 14, 185-215.

Boellinghaus, I., Jones, F. W., \& Hutton, J. (2013). Cultivating self-care and compassion in psychological therapists in training: The experience of practicing loving-kindness meditation. Training and Education in Professional Psychology, 7(4), 267-277. https://doi.org/10.1037/a0033092.

Bohlmeijer, E. T., Lamers, S. M. A., \& Fledderus, M. (2015). Flourishing in people with depressive symptomatology increases with Acceptance and Commitment Therapy. Post-hoc analyses of a randomized controlled trial. Behaviour Research and Therapy, 65, 101-106. https://doi.org/10.1016/j.brat.2014.12.014.

British Association for Counselling and Psychotherapy. (2018). BACP ethical framework for the counselling professions. Retrieved from https://www.bacp.co.uk/events-and-resources/ethics-and-standards/ethicalframework-for-the-counselling-professions/. Accessed 31 Jul 2020.

Brooks, J., Holttum, S., \& Lavender, A. (2002). Personality style, psychological adaptation and expectations of trainee clinical psychologists. Clinical Psychology \& Psychotherapy, 9(4), 253-270. https://doi.org/10.1002 /cpp.318.

Brown, S. (2017). Is counselling women's work? Retrieved from https:/www.bacp.co.uk/bacp-journals/therapytoday/2017/march-2017/is-counselling-womens-work/. Accessed 31 Jul 2020.

Bryan, C., O’Shea, D., \& MacIntyre, T. (2017). Stressing the relevance of resilience: A systematic review of resilience across the domains of sport and work. International Review of Sport and Exercise Psychology. https://doi.org/10.1080/1750984X.2017.1381140.

Casuso-Holgado, M. J., Cuesta-Vargas, A. I., Moreno-Morales, N., Labajos-Manzanares, M. T., Barón-López, F. J., \& Vega-Cuesta, M. (2013). The association between academic engagement and achievement in health sciences students. BMC Medical Education, 13(1), 33. https://doi.org/10.1186/1472-6920-13-33. 
College of Occupational Therapists. (2014). College of occupational therapists' learning and development standards for pre-registration education (Vol. 32).

Complete University Guide. (2018). Five reasons to study a counselling degree. Retrieved from https://www. thecompleteuniversityguide.co.uk/courses/counselling/five-reasons-to-study-a-counselling-degree/. Accessed 31 Jul 2020.

Cooke, P., Melchert, T., \& Connor, K. (2016). Measuring well-being: A review of instruments. The Counseling Psychologist, 44(5), 730-757. https://doi.org/10.1177/0011000016633507.

Corno, G. Etchemendy, E., Espinoza, M., Herrero, R., Molinari, G., Carrillo, A. ... Baños, R.M. (2018). Effect of a web-based positive psychology intervention on prenatal well-being: A case series study. Women and Birth, 31(1), e1-e8. https://doi.org/10.1016/j.wombi.2017.06.005.

Christopher, J., \& Maris, J. (2010). Integrating mindfulness as self-care into counselling and psychotherapy training. Counselling and Psychotherapy Research, 10(2), 114-125. https://doi.org/10.1080 $/ 14733141003750285$.

Datu, J. A. D. (2018). Flourishing is associated with higher academic achievement and engagement in Filipino undergraduate and high school students. Journal of Happiness Studies, 19(1), 27-39. https://doi.org/10.1007 /s10902-016-9805-2.

Deci, E. L., \& Ryan, R. M. (1985). Intrinsic motivation and self-determination in human behavior. New York: Plenum Publishing.

Denovan, A., \& Macaskill, A. (2017). Stress and subjective well-being among first year UK undergraduate students. Journal of Happiness Studies, 18(2), 505-525. https://doi.org/10.1007/s10902-016-9736-y.

Dunn, W. (2017). Strengths-based approaches: What if even the "bad" things are good things? British Journal of Occupational Therapy, 80(7), 395-396. https://doi.org/10.1177/0308022617702660.

Ehret, A. M., Joormann, J., \& Berking, M. (2015). Examining risk and resilience factors for depression: The role of self-criticism and self-compassion. Cognition and Emotion, 29(8), 1496-1504. https://doi.org/10.1080 /02699931.2014.992394.

Faul, F., Erdfelder, E., Buchner, A., \& Lang, A.-G. (2009). Statistical power analyses using G*Power 3.1: Tests for correlation and regression analyses. Behavior Research Methods, 41, 1149-1160. https://doi.org/10.3758 /BRM.41.4.1149.

Fergus, S., \& Zimmerman, M. A. (2005). Adolescent resilience: A framework for understanding healthy development in the face of risk. Annual Review of Public Health, 26(1), 399-419. https://doi.org/10.1146 /annurev.publhealth.26.021304.144357.

Fong, M., \& Loi, N. M. (2016). The mediating role of self-compassion in student psychological health. Australian Psychologist, 51(6), 431-441. https://doi.org/10.1111/ap.12185.

Forsman, A. K., Wahlbeck, K., Aaro, L. E., Alonso, J., Barry, M. M., Brunn, M., et al. (2015). Research priorities for public mental health in Europe: Recommendations of the ROAMER project. The European Journal of Public Health, 25(2), 249-254. https://doi.org/10.1093/eurpub/cku232.

Fowler, J., \& Christakis, N. (2010). Cooperative behavior cascades in human social networks. Proceedings of the National Academy of Sciences, 107(12), 5334-5338. https://doi.org/10.1073/pnas.0913149107.

Gagné, M. (2003). The role of autonomy support and autonomy orientation in prosocial behavior engagement. Motivation and Emotion, 27(3), 199-223. https://doi.org/10.1023/A:1025007614869.

Galante, J., Dufour, G., Vainre, M., Wagner, A. P., Stochl, J., Benton, A., et al. (2018). A mindfulness-based intervention to increase resilience to stress in university students (the Mindful Student Study): A pragmatic randomised controlled trial. The Lancet Public Health, 3(2), e72-e81. https://doi.org/10.1016/S2468-2667 (17)30231-1.

Gilbert, P. (2009). Introducing compassion-focused therapy. Advances in Psychiatric Treatment, 15(3), $199-208$. https://doi.org/10.1192/apt.bp.107.005264.

Gilbert, P. (2000). Social mentalities: Internal "social" conflicts and the role of inner warmth and compassion in cognitive therapy. In P. Gilbert \& K. G. Bailey (Eds.), Genes on the couch: Explorations in evolutionary psychotherapy (pp. 118-150). Hove: Brunner-Routledge.

Grant, L., \& Kinman, G. (2014). Emotional resilience in the helping professions and how it can be enhanced. Health and Social Care Education, 3(1), 23-34. https://doi.org/10.11120/hsce.2014.00040.

Grant, V. J., Robinson, E., \& Muir, P. (2004). Sex ratios in healthcare occupations: Population based study. British Medical Journal, 328(7432), 141-142. https://doi.org/10.1136/bmj.328.7432.141.

Harrison, E. (2013). Bouncing back? Recession, resilience and everyday lives. Critical Social Policy, 33(1), 97113. https://doi.org/10.1177/0261018312439365.

Haktanir, A., Lenz, A. S., Can, N., \& Watson, J. (2016). Development and evaluation of Turkish language versions of three positive psychology assessments. International Journal for the Advancement of Counselling, 38(4), 286-297. https://doi.org/10.1007/s10447-016-9272-9. 
Hall, S., McKinstry, C., \& Hyett, N. (2015). An occupational perspective of youth positive mental health: A critical review. British Journal of Occupational Therapy, 78(5), 276-285. https://doi.org/10.1177 /0308022615573540.

Hayes, A. (2018). Introduction to Mediation, Moderation, and Conditional Process Analysis. New York: Guilford.

Hayter, M. R., \& Dorstyn, D. S. (2014). Resilience, self-esteem and self-compassion in adults with spina bifida. Spinal Cord, 52(2), 167-171. https://doi.org/10.1038/sc.2013.152.

Higher Education Statistics Agency. (2017). Data and Analysis. Retrieved from https://www.hesa.ac.uk/dataand-analysis/students/courses. Accessed 31 Jul 2020.

Hoaglin, D. C., \& Iglewicz, B. (2012). Fine-tuning some resistant rules for outlier labeling. Journal of the American Statistical Association, 82(400), 1147-1149. https://doi.org/10.1080/01621459.1987.10478551.

Houkes, I., Jassen, P. P. M., de Jonge, J., \& Bakker, A. B. (2003). Specific determinants of intrinsic work motivation, emotional exhaustion and turnover intention: a multisample longitudinal study. Journal of Occupational and Organizational Psychology, 76, 427-450. https://doi.org/10.1348/096317903322591578.

Jennings, P., \& Greenberg, M. (2009). The prosocial classroom: Teacher social and emotional competence in relation to student and classroom outcomes. Review of Educational Research, 79(1), 491-525. https:/doi. org/10.3102/0034654308325693.

Joseph, S., \& Linley, A. (2006). Positive psychological approaches to therapy. Counselling and Psychotherapy Research, 5(1), 5-10. https://doi.org/10.1080/14733140512331343831.

Kashdan, T. B., \& Ciarrochi, J. (2013). Mindfulness, acceptance, and positive psychology: The seven foundations of well-being. Oakland: Context Press.

Khalaila, R. (2015). The relationship between academic self-concept, intrinsic motivation, test anxiety, and academic achievement among nursing students: Mediating and moderating effects. Nurse Education Today, 35(3), 432-438. https://doi.org/10.1016/j.nedt.2014.11.001.

Keyes, C. L. M., Dhingra, S. S., \& Simoes, E. J. (2010). Change in level of positive mental health as a predictor of future risk of mental illness. American Journal of Public Health, 100(12), 2366-2371. https://doi. org/10.2105/AJPH.2010.192245.

Kobau, R., Seligman, M. E., Peterson, C., Diener, E., Zack, M., Chapman, D., \& Thompson, W. (2011). Mental health promotion in public health: Perspectives and strategies from positive psychology. American Journal of Public Health, 101(8), e1-e9. https://doi.org/10.2105/AJPH.2010.300083.

Kotera, Y., Green, P., Rhodes, C., Williams, A., Chircop, J., Spink, R., Rawson, R. \& Okere, U. (2020b). Dealing with isolation using online morning huddles for university lecturers during physical distancing by COVID-19: Field notes. The International Review of Research in Open and Distributed Learning. http://hdl. handle.net/10545/625008.

Kotera, Y., \& Sheffield, D. (2020). Revisiting the self-compassion scale-short form: Stronger associations with self-inadequacy and resilience. SN Comprehensive Clinical Medicine, 2(6), 761-769. https://doi.org/10.1007 /s42399-020-00309-w.

Kotera, Y., Van Laethem, M., \& Ohshima, R. (2020a). Cross-cultural comparison of mental health between Japanese and Dutch workers: Relationships with mental health shame, self-compassion, work engagement and motivation. Cross Cultural \& Strategic Management. https://doi.org/10.1108/CCSM-02-2020-0055.

Kotera, Y., Conway, E., \& Van Gordon, W. (2019). Mental health of UK university business students: Relationship with shame, motivation and self-compassion. Journal of Education for Business, 94(1), 1120. https://doi.org/10.1080/08832323.2018.1496898.

Kotera, Y., Green, P., \& Sheffield, D. (2019b). Mental health attitudes, self-criticism, compassion, and role identity among UK social work students. British Journal of Social Work, 49(2), 351-370. https://oi. org/10.1093/bjsw/bcy072.

Kotera, Y., Green, P., \& Sheffield, D. (2019c). Mental health of therapeutic students: Relationships with attitudes, self-criticism, self-compassion, and caregiver identity. British Journal of Guidance and Counselling. https://doi.org/10.1080/03069885.2019.1704683.

Kotera, Y., Green, P., \& Sheffield, D. (2019d). Mental health shame of UK construction workers: Relationship with masculinity, work motivation, and self-compassion. Journal of Work and Organizational Psychology, 35(2), 135-143. https://doi.org/10.5093/jwop2019a15.

Kotera, Y., \& Ting, S. H. (2019). Positive psychology of Malaysian students: Impacts of engagement, motivation, self-compassion and wellbeing on mental health. International Journal of Mental Health and Addiction. https://doi.org/10.1007/s11469-019-00169-z.

Kotera, Y., Adhikari, P., \& Van Gordon, W. (2018c). Motivation types and mental health of UK hospitality workers. International Journal of Mental Health and Addiction, 16(3), 751-763. https://doi.org/10.1007 /s11469-018-9874-z. 
Kotera, Y., Adhikari, P., \& Van Gordon, W. (2018d). The relationship between work motivation and worker profile in UK hospitality workers. International Journal of Education, Psychology and Counseling, 2(6), 231-243.

Kotera, Y., Conway, E., \& Van Gordon, W. (2018a). Ethical judgement in UK business students: Relationship with motivation, self-compassion and mental health. International Journal of Mental Health and Addiction. https://doi.org/10.1007/s11469-018-0034-2.

Kotera, Y., Green, P., \& Van Gordon, W. (2018b). Mental wellbeing of caring profession students: Relationship with caregiver identity, self-compassion, and intrinsic motivation. Mindfulness and Compassion, 3(2), 7-30.

Lenz, A. S., Watson, J., Luo, Y., Norris, C., \& Nkyi, A. (2018). Cross-cultural validation of four positive psychology assessments for use with a Ghanaian population. International Journal for the Advancement of Counselling, 40(2), 148-161. https://doi.org/10.1007/s10447-017-9317-8.

Liébana-Presa, C., Fernández-Martínez, E., Gándara, A., Muñoz-Villanueva, C., Vázquez-Casares, A. M., \& Rodríguez-Borrego, A. (2014). Psychological distress in health sciences college students and its relationship with academic engagement. Revista da Escola de Enfermagem da USP, 48, 715-722. https://doi. org/10.1590/S0080-623420140000400020.

Locke, E. A., \& Latham, G. P. (2004). What should we do about motivation theory? Six recommendations for the twenty-first century. The Academy of Management Review, 29(3), 388-403. https://doi.org/10.2307 /20159050.

Maki, Y., \& Endo, H. (2018). The contribution of occupational therapy to building a dementia-positive community. British Journal of Occupational Therapy, 81(10), 566-570. https://doi.org/10.1177 /0308022618774508.

Marais, G. A. B., Shankland, R., Haag, P., Fiault, R., \& Juniper, B. (2018). A survey and a positive psychology intervention on French PhD student well-being. International Journal of Doctoral Studies, 13, 109-138. https://doi.org/10.28945/3948.

McGhee, P. (2015). What are the most popular degree courses? Retrieved from http://www.bbc.co. uk/news/education-32230793. Accessed 31 Jul 2020.

Mckenna, J., \& Mellson, J. A. (2013). Emotional intelligence and the occupational therapist. British Journal of Occupational Therapy, 76(9), 427-430. https://doi.org/10.4276/030802213X13782044946382.

Melnyk, B. M., Orsolini, L., Tan, A., Arslanian-Engoren, C., Melkus, G. D. E., Dunbar-Jacob, J., et al. (2018). A national study links nurses' physical and mental health to medical errors and perceived worksite wellness. Journal of Occupational and Environmental Medicine. https://doi.org/10.1097/JOM.0000000000001198.

Ministry of Education, Culture, Sports, Science and Technology-Japan. (2015). Monbukagakusho toukei youran [Statistics from Ministry of Education, Culture, Sports, Science and Technology-Japan]. Retrieved from http://www.mext.go.jp/b_menu/toukei/002/002b/1356065.htm. Accessed 31 Jul 2020.

Muller, G. (2016). What's the most popular subject to study in a university in Germany? In Quora Retrieved from https://www.quora.com/Whats-the-most-popular-subject-to-study-in-a-university-in-Germany. Accessed 31 Jul 2020.

Muris, P., van den Broek, M., Otgaar, H., Oudenhoven, I., \& Lennartz, J. (2018). Good and bad sides of selfcompassion: A face validity check of the Self-Compassion Scale and an investigation of its relations to coping and emotional symptoms in non-clinical adolescents. Journal of Child and Family Studies, 27(8), 2411-2421. https://doi.org/10.1007/s10826-018-1099-z.

National Center for Education Statistics. (2016). Digest of Education Statistics, 2015 Retrieved from https://nces. ed.gov/programs/digest/d15/ch_3.asp. Accessed 31 Jul 2020.

Neel, C. G.-O., \& Fuligni, A. (2013). A longitudinal study of school belonging and academic motivation across high school. Child Development, 84(2), 678-692. https://doi.org/10.1111/j.1467-8624.2012.01862.x.

Neff, K. D., \& Mcgehee, P. (2010). Self-compassion and psychological resilience among adolescents and young adults. Self and Identity, 9(3), 225-240. https://doi.org/10.1080/15298860902979307.

Newman, F. M., Wehlage, G. G., \& Lamborn, S. D. (1992). The significance and sources of student engagement. In F. M. Newman (Ed.), Student engagement and achievement in American secondary schools (pp. 11-39). New York: Teachers College Press.

Pooley, J., \& Cohen, L. (2010). Resilience: A definition in context. The Australian Community Psychologist, 22(1), 30-37.

Raes, F., Pommier, E., Neff, K. D., \& Van Gucht, D. (2011). Construction and factorial validation of a short form of the Self-Compassion Scale. Clinical Psychology \& Psychotherapy, 18(3), 250-255. https://doi. org/10.1002/cpp.702.

Robertson, I. T., Cooper, C., Sarkar, M., \& Curran, T. (2015). Resilience training in the workplace from 2003 to 2014: A systematic review. Journal of Occupational and Organizational Psychology, 88(3), 533-562. https://doi.org/10.1111/joop.12120. 
Rogers, A., DeLay, D., \& Martin, C. (2017). Traditional masculinity during the middle school transition: Associations with depressive symptoms and academic engagement. Journal of Youth and Adolescence, 46, 709-724. https://doi.org/10.1007/s10964-016-0545-8.

Russ, E., Lonne, B., \& Darlington, Y. (2009). Using resilience to reconceptualise child protection workforce capacity. Australian Social Work, 62(3), 324-338. https://doi.org/10.1080/03124070903060042.

Schaufeli, W. B., Salanova, M., Gonzalez-Roma, V., \& Bakker, A. B. (2002). The measurement of engagement and burnout: A two sample confirmatory factor analytic approach. Journal of Happiness Studies, 3, 71-92. https://doi.org/10.1023/A:1015630930326.

Schotanus-Dijkstra, M., ten Have, M., Lamers, S. M. A., de Graaf, R., \& Bohlmeijer, E. T. (2016). The longitudinal relationship between flourishing mental health and incident mood, anxiety and substance use disorders. The European Journal of Public Health, 27(3), 563-568. https://doi.org/10.1093/eurpub/ckw202.

Seligman, M. E. P., \& Csikszentmihalyi, M. (2000). Positive psychology: An introduction. American Psychologist, 55(1), 5-14. https://doi.org/10.1037/0003-066X.55.1.5.

Suárez-Colorado, Y., Caballero-Domínguez, C., Palacio-Sañudo, J., \& Abello-Llanos, R. (2019). The academic burnout, engagement, and mental health changes during a school semester. Duazary, 16(1), 21-37. https://doi.org/10.21676/2389783X.2530.

Schaufeli, W., \& Bakker, A. (2004). Utrecht Work Engagement Scale: Preliminary Manual. Utrecht: Occupational Health Psychology Unit, Utrecht University.

Smith, B. W., Dalen, J., Wiggins, K., Tooley, E., Christopher, P., \& Bernard, J. (2008). The brief resilience scale: Assessing the ability to bounce back. International Journal of Behavioral Medicine, 15(3), 194-200. https://doi.org/10.1080/10705500802222972.

Spoorthy, M. S., Pratapa, S. K., \& Mahant, S. (2020). Mental health problems faced by healthcare workers due to the COVID-19 pandemic: A review. Asian Journal of Psychiatry. https://doi.org/10.1016/j.ajp.2020.102119.

Stew, G. (2011). Mindfulness training for occupational therapy students. British Journal of Occupational Therapy, 74(6), 269-276. https://doi.org/10.4276/030802211X13074383957869.

Stewart-Brown, S., Tennant, A., Tennant, R., Platt, S., Parkinson, J., \& Weich, S. (2009). Internal construct validity of the Warwick-Edinburgh Mental Well-being Scale (WEMWBS): A Rasch analysis using data from the Scottish Health Education Population Survey. Health and Quality of Life Outcomes, 7(1), 15. https://doi.org/10.1186/1477-7525-7-15.

Stewart-Brown, S., \& Janmohamed, K. (2008). Warwick-Edinburgh Mental Well-being Scale (WEMWBS) user guide version 1. Warwick: Warwick Medical School.

The Quality Assurance Agency for Higher Education. (2013). Subject benchmark statement: Counselling and Psychotherapy. Gloucester: Author.

Trompetter, H. R., de Kleine, E., \& Bohlmeijer, E. T. (2017). Why does positive mental health buffer against psychopathology? An exploratory study on self-compassion as a resilience mechanism and adaptive emotion regulation strategy. Cognitive Therapy and Research, 41(3), 459-468. https://doi.org/10.1007/s10608-0169774-0.

Tugade, M. M., \& Fredrickson, B. L. (2004). Resilient individuals use positive emotions to bounce back from negative emotional experiences. Journal of Personality and Social Psychology, 86(2), 320-333. https://oi. org/10.1037/0022-3514.86.2.320.

Tukey, J. W. (1962). The future of data analysis. The Annals of Mathematical Statistics, 33, 1-67. https://doi. org/10.1214/aoms/1177704711.

Turner, M., Scott-Young, C., \& Holdsworth, S. (2017). Promoting wellbeing at university: The role of resilience for students of the built environment. Construction Management and Economics, 35(11-12), 707-718. https://doi.org/10.1080/01446193.2017.1353698.

Ungar, M. (2008). Resilience across cultures. British Journal of Social Work, 38(2), 218-235. https://oi. org/10.1093/bjsw/bcl343.

Utvær, K. (2014). Explaining health and social care students' experiences of meaningfulness in vocational education: The importance of life goals, learning support, perceived competence, and autonomous motivation. Scandinavian Journal of Educational Research, 58(6), 639-658. https://doi.org/10.1080 /00313831.2013.821086.

Vallerand, R. J. (1997). Toward a hierarchical model of intrinsic and extrinsic motivation. In M. P. Zanna (Ed.), Advances in experimental social psychology (pp. 271-360). San Diego: Academic Press.

Vallerand, R., Pelletier, L., Blais, M., Briere, N., Senecal, C., \& Vallieres, E. (1992). The Academic Motivation Scale: A measure of intrinsic, extrinsic, and amotivation in education. Educational and Psychological Measurement, 52(4), 1003-1017.

Van Breda, A. D. (2018). A critical review of resilience theory and its relevance for social work. Social Work/ Maatskaplike Werk, 54(1). https://doi.org/10.15270/54-1-611. 
Vandenberghe, L., \& Silvestre, R. L. S. (2014). Therapists' positive emotions in-session: Why they happen and what they are good for. Counselling and Psychotherapy Research, 14(2), 119-127. https://doi.org/10.1080 $/ 14733145.2013 .790455$.

Zhang, Y., Luo, X., Che, X., \& Duan, W. (2016). Protective effect of self-compassion to emotional response among students with chronic academic stress. Frontiers in Psychology, 7(1802). https://doi.org/10.3389 /fpsyg.2016.01802.

Publisher's Note Springer Nature remains neutral with regard to jurisdictional claims in published maps and institutional affiliations. 